LA W RENCE LIVERMORE NATIONAL LABORATORY

High-Z Non-Equilibrium Physics and Bright X-ray Sources with New Laser Targets

J. D. Colvin

August 29, 2012 
This document was prepared as an account of work sponsored by an agency of the United States government. Neither the United States government nor Lawrence Livermore National Security, LLC, nor any of their employees makes any warranty, expressed or implied, or assumes any legal liability or responsibility for the accuracy, completeness, or usefulness of any information, apparatus, product, or process disclosed, or represents that its use would not infringe privately owned rights. Reference herein to any specific commercial product, process, or service by trade name, trademark, manufacturer, or otherwise does not necessarily constitute or imply its endorsement, recommendation, or favoring by the United States government or Lawrence Livermore National Security, LLC. The views and opinions of authors expressed herein do not necessarily state or reflect those of the United States government or Lawrence Livermore National Security, LLC, and shall not be used for advertising or product endorsement purposes.

This work performed under the auspices of the U.S. Department of Energy by Lawrence Livermore National Laboratory under Contract DE-AC52-07NA27344. 
LLNL-TR-577612

September 1, 2012

FY 2012 Annual Report on DTRA Basic Research Project \#BRCALL08-Per3-C-2-0006 "High-Z Non-Equilibrium Physics and Bright X-ray Sources with New Laser Targets" IACRO \#10-4238|

\author{
Jeffrey D. ('Jeff') Colvin, PI \\ Lawrence Livermore National Laboratory \\ L-356, P.O. Box 808, Livermore, CA 94551 USA
}

(925) 422-3273

This work was performed under the auspices of the U.S. Department of Energy by LLNL under Contract No. DE-AC52-07NA27344. 


\section{Goals of the Project}

This project has two major goals, as follows.

- Final Goal: obtain spectrally resolved, absolutely calibrated x-ray emission data from uniquely uniform $\mathrm{mm}$-scale near-critical-density high-Z plasmas not in local thermodynamic equilibrium (LTE) to benchmark modern detailed atomic physics models.

- Scientific significance: advance understanding of non-LTE atomic physics

- Intermediate Goal: develop new nano-fabrication techniques to make suitable laser targets that form the required highly uniform non-LTE plasmas when illuminated by high-intensity laser light.

- Scientific significance: advance understanding of nano-science

- Relation to DTRA C-WMD mission: The new knowledge will allow us to make x-ray sources that are bright at the photon energies of most interest for testing radiation hardening technologies, the spectral energy range where current $x$-ray sources are weak.

\section{Accomplishments This Year}

This project consists of three principal tasks: laser target development, laser experiments, and computational design and modeling. Progress has been made in FY 2012 on laser target development and modeling.

\section{Laser Target Development}

The main-line approach in target development is a four-step ion lithography process. In Step 1 we use an ion accelerator at LLNL to track Xe ions through a 3- or 6- $\mu$ m-thick commercial polycarbonate substrate. In Step 2 we etch out the intersecting damage tracks left by the ions. Step 3 is to electro-deposit the metal into the $\sim 10$-nm-diameter holes left by the etch process. Finally, we assemble several etched and plated substrates into the final target dimensions, and dissolve the substrates, leaving a self-supporting array of metal nanowires with the required target dimensions and density.

The principal accomplishment this year was demonstrating success in making free-standing selfsupporting structures of intersecting nanowires, as shown in the scanning electron microscope (SEM) images of Figure 1. The SEM image in Figure 1a shows intersecting 85-nm-diameter $\mathrm{Cu}$ nanowires. This structure has an overall density about $8 \%$ of full density. The intersections are seen more clearly in the thicker nanowires in the SEM image of Figure $1 \mathrm{~b}$. This is a significant 
advance toward the intermediate goal, because we have now shown that the basic ionlithography process will work to make low density pure metal foams. There is a tradeoff between nanowire diameter and number of intersections for a given ion areal density; we have calculated that, by optimizing the variables, we should be able to make foams with densities below $5 \%$ of full density, and we are attempting to make such a $\mathrm{Cu}$ foam now.

a.

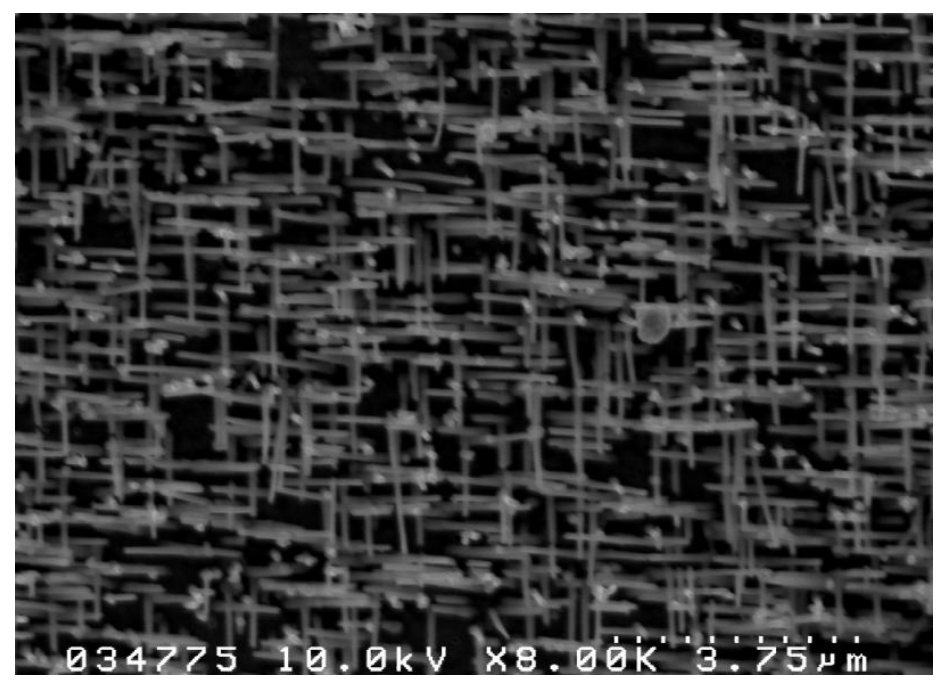

b.

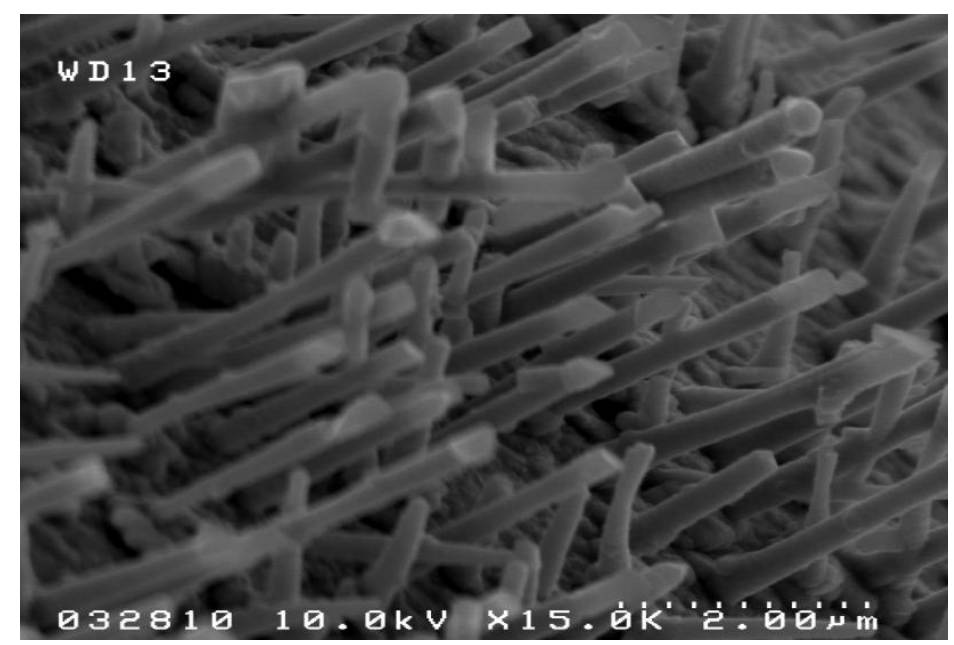

Figure 1. SEM images of a) 85-nm-diameter and b) 250-nm-diameter Cu nanowire foams. One way to get the additional factor of 20 -times reduction in overall density is by crumpling, and experiments have begun on this process. An alternate way is to make the nanowires as hollow nanotubes. Another major accomplishment this year is the success in making hollow 
nanotubes, as shown in Figure 2. In this figure is shown a SEM image of 2- $\mu \mathrm{m}$-long Co nanotubes grown inside 400-nm-diameter Cu nanotubes, albeit not intersecting.

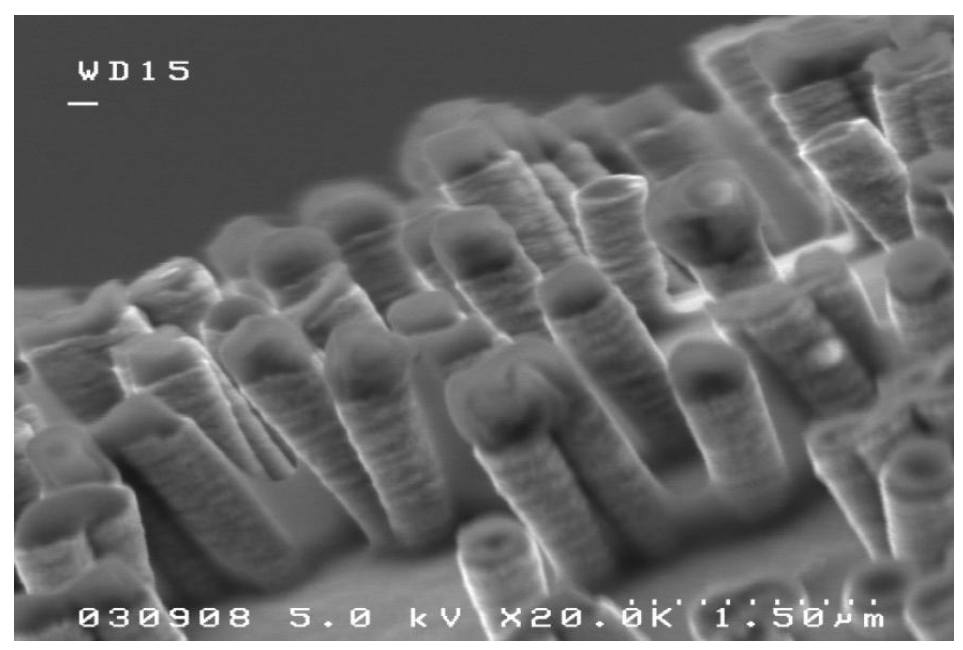

Figure 2. SEM image of 2- $\mu \mathrm{m}$-long Co nanotubes grown inside 400-nm-diameter Cu nanotubes.

An additional approach to foam target development is to mechanically trap Cu nanowires or nanoparticles in the pores of low-density lower-Z foam. A major accomplishment this year was developing a method to synthesize $\mathrm{Cu}$-doped $\mathrm{C}$ nanotube foams with minimal agglomeration of Cu nanoparticles and minimal foam shrinkage. Figure 3 shows a SEM image of one such Culoaded C foam (the Cu nano-particles are the small bright spots). Figure 4 shows a Rutherford Backscatter Spectrum from one such foam, from which we infer that the $\mathrm{Cu}$ is distributed very uniformly in depth into the $\mathrm{C}$ foam, at least to the depth of the probe beam. We have already demonstrated that we can make $C$ foams at densities as low as $30-50 \mathrm{mg} \mathrm{cm}^{-3}$ (but are still experimenting with getting the right fractional concentration of $\mathrm{Cu}$ without agglomeration and foam shrinkage). We have also demonstrated that lower densities are possible by introducing carbon nanotubes and/or sacrificial plastic micro-beads before the gelation process. We are currently working on optimization of the synthesis steps to meet the stringent requirements for target density, uniformity, and dimensions. 


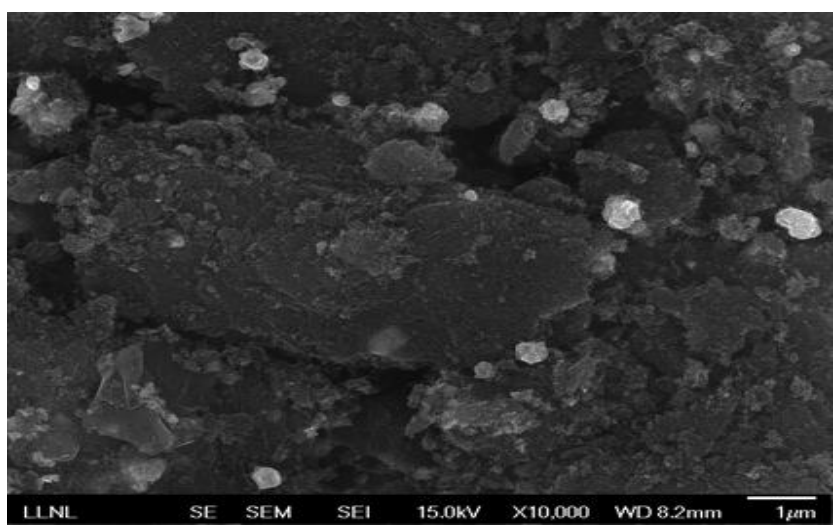

Figure 3. SEM image of C foam doped with Cu nanoparticles.

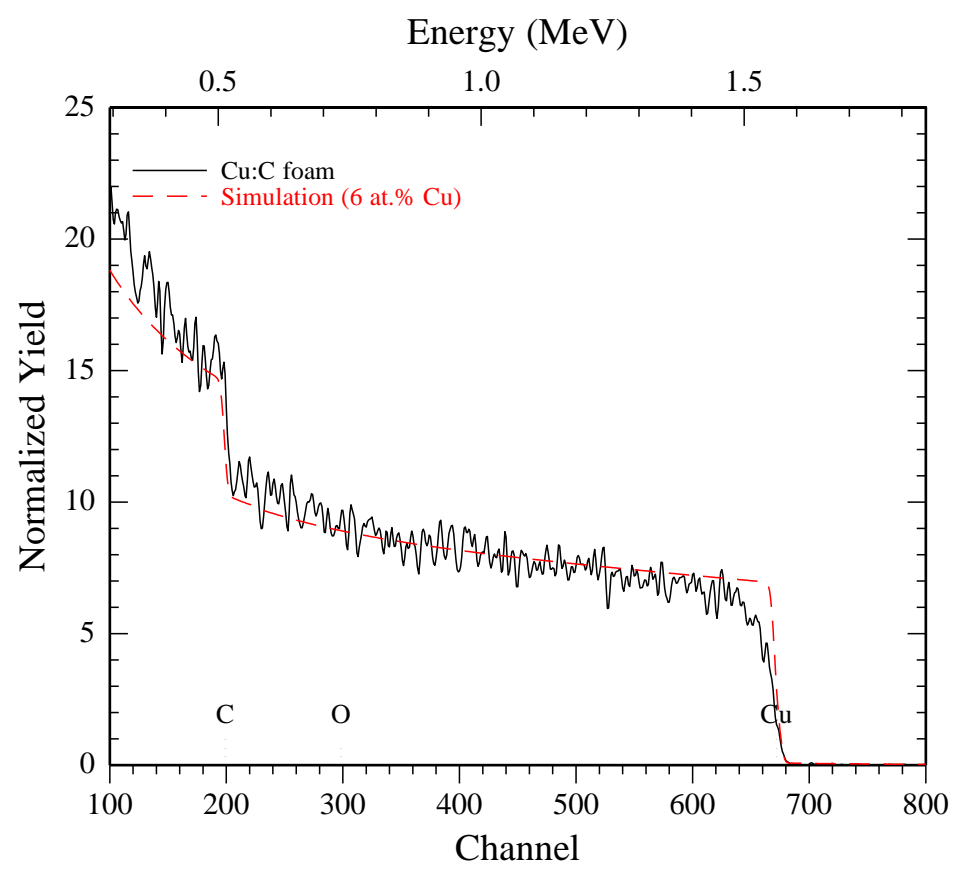

Figure 4. Rutherford backscatter spectrum (RBS) from a $\mathrm{C}$ foam doped with $\sim 6$ atom $\% \mathrm{Cu}$ nanoparticles (total density $85 \mathrm{mg} \mathrm{cm}^{-3}$ ).

\section{Target Design and Modeling}

The modeling effort in FY2012 has focused on further optimizing the Cu foam target we designed last year to maximize the x-ray conversion efficiency. In last year's Annual Report we presented the following accomplishments:

- Designed a baseline Omega Laser target of pure Cu foam contained inside a 2-mm x 2$\mathrm{mm}$ cylindrical Be can. 
- Determined the optimum foam density to be $\sim 1 / 1000$ of full solid density $\left(\sim 10 \mathrm{mg} \mathrm{cm}^{-3}\right)$.

- Simulated a Cu K-shell $\mathrm{x}$-ray conversion efficiency of $\sim 0.7 \%$, comparable to previous experience on Omega.

- Found that, because of rapid adiabatic expansion of the heated plasma, the range of acceptable initial foam densities is fairly broad, and the foam rapidly homogenizes, so the initial foam uniformity is not an issue.

The design and modeling accomplishments this year are summarized in Figure 5 . We see there that 1 ) eliminating the Be can (so that the target looks somewhat like cotton candy on a stick) reduces thermal conduction losses from the hot plasma to the cooler can and hence gives a higher K-shell x-ray conversion efficiency --- by nearly a factor of two at the optimum density; and 2) switching from silica aerogel foams to the lower-Z carbon nanotube foams for the alternate target design reduces the radiation losses somewhat, giving higher K-shell x-ray conversion efficiency.

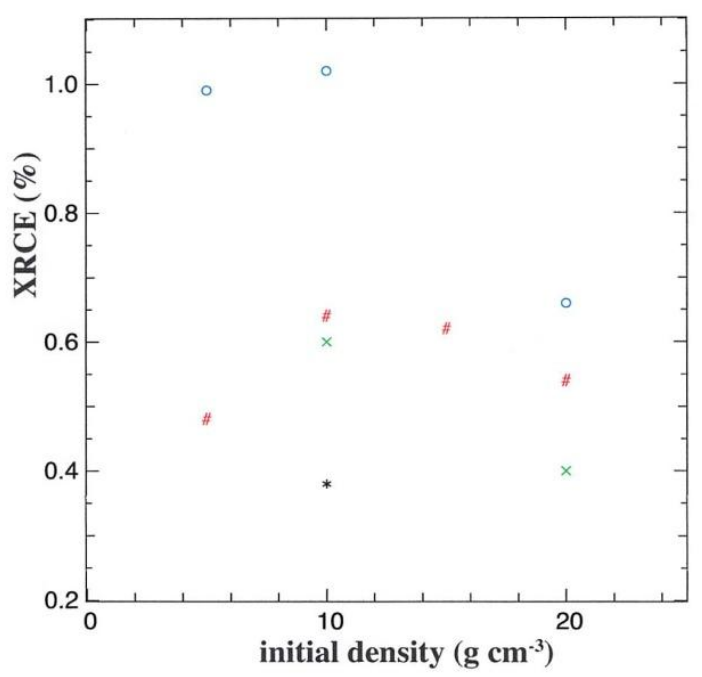

Figure 5. K-shell $\mathrm{x}$-ray conversion efficiency (\%) as a function of initial foam density $\left(\mathrm{mg} \mathrm{cm}^{-3}\right)$. o - pure Cu targets, no can; \# - pure Cu targets in Be can; $x$ - Cu-loaded C foam targets, no can;

* - Cu-loaded silica foam target in Be can.

\section{Personnel Supported}

The following people have been supported by this grant during this FY according to their time spent on the project.

At LLNL:

Dr. Jeff Colvin, PI, staff scientist 
Dr. Sergei Kucheyev, staff scientist

Dr. Supakit Charnvanichborikarn, postdoctoral research fellow

Dr. Frédéric Perez, postdoctoral research fellow

At University of California-Davis:

Prof. Kai Liu

Mr. Edward Burks, graduate student

Mr. Dustin Gilbert, graduate student

Mr. Chad Flores, graduate student

At Sandia National Laboratories-California:

Dr. Tom Felter. Staff scientist

This project is providing professional career development opportunities for the two LLNL postdoctoral research fellows, and also forms part of the basis for the training and thesis work for the UCD graduate students.

\section{Dissemination of Research Results}

The research results generated by this project have been presented at the American Physical Society Division of Plasma Physics Annual Meeting in Salt Lake City, Utah on November 16, 2011. The abstract of this presentation has been published:

J. Colvin, S. Charnvanichborikarn, T. Felter, C. Flores, K. Fournier, D. Gilbert, S. Kucheyev, \& K. Liu, “On Optimizing K-shell X-ray Conversion Efficiency with New Nano-structured Laser Targets", Bull. of the APS 56, 259 (2011).

\section{Plans for Next Year}

In what remains of this fiscal year we plan to complete the foam fabrication development and assemble Omega-scale laser targets. Next year we plan to 1) conduct Omega laser experiments and 2) begin fabrication of larger-scale targets for the National Ignition Facility (NIF) laser.

1) A new postdoctoral research fellow, Dr. Frédéric Perez, joined the project this year specifically to plan and carry out the laser experiments. Next year's laser experiments will be conducted at the Omega Laser Facility at the University of Rochester in Rochester, New York. The Omega laser delivers $\sim 20 \mathrm{~kJ}$ of $1 / 3-\mu \mathrm{m}$ laser light to the target in three beam cones per 
side. Dr. Perez has already begun work on planning and configuring the diagnostics for these experiments. We have shot time allocated on the FY2013 Omega shot schedule.

2) Modeling predicts that a pure Cu NIF target will get twice as hot for much longer duration than the smaller but equivalent-density Omega target --- above $6 \mathrm{keV}$ for $\sim 4 \mathrm{~ns}$ vs. above $3 \mathrm{keV}$ for $\sim 1$ ns --- and will produce much more Ly- $\alpha$ radiation, leading to a K-shell $x$-ray conversion efficiency of $\sim 2.2 \%$ vs. $\sim 0.7 \%$ on Omega. Accordingly, we plan to use the same target fabrication techniques that we are developing this year to fabricate larger-scale targets suitable for NIF. 